\title{
МИГРАЦИЯ НА ПОСТСОВЕТСКОМ ПРОСТРАНСТВЕ
}

\section{Рецензия на книгу}

\section{«Migration from the Newly Independent States: \\ 25 years after the collapse of the USSR» \\ OKCAHA XAPAEBA}

\begin{abstract}
В рецензии представлена работа большого коллектива авторов из разных стран, изданная под редакиией М.Б. Денисенко, М. Лайта (M. Light) и C. Строица (S. Strozza). В книге дается комплексный анализ развития миграционных проиессов в новых независимых государствах, возникших на территории бывщего СССР. С привлечением широкого спектра источников проведено исследование масштабов, тенденций и факторов миграчии, социально-демографических характеристик мигрантов, а также положения мигрантов в принимающих странах. Большое внимание уделено вопросам влияния миграции на страны выхода и назначения мигрантов.
\end{abstract}

Ключевые слова: миграция, новые независимые государства, диаспоры, интеграцияя.

Распад СССР, появление новых независимых государств и открытие внешних границ кардинальным образом изменили географию, объем и характер миграционных процессов на постсоветском пространстве, а также заметно повлияли на ситуацию за его пределами. У миллионов людей «изменились сложившиеся отношения с их территориями» (Танги 2010), что сделало бывшие советские республики одним из центров мирового миграционного движения (Денисенко, Чудиновских 2012). Рецензируемая книга является итогом работы специалистов из 15 стран - политологов, демографов, географов, социологов, экономистов, объединенных стремлением создать комплексную картину развития миграционных процессов в новых независимых государствах, возникших на территории бывшего СССР. Авторы применяют широкий спектр методов исследования и разнообразие подходов, используют все доступные источники информации: переписи населения, административную статистику, результаты выборочных обследований и глубинных интервью. Это дает возможность рассмотрения вопросов с разных позиций, что добавляет книге определенную самобытность.

Миграционная ситуация на постсоветском пространстве достаточно активно изучается в последние десятилетия, однако масштабы миграционных перемещений и значимость их последствий для экономики и политики принимающих и посылающих стран требуют дальнейшего научного осмысления и подведения некоторых итогов. В данной работе была предпринята попытка анализа всего многообразия потоков и эволюции постсоветской миграции почти за тридцатилетний период с момента распада Советского Союза. Книга объединяет два сюжета: миграцию между новыми независимыми государствами и между новыми независимыми государствами и странами за пределами бывшего СССР. Анализ миграционной ситуации на всем постсоветском пространстве дополнен рассмотрением наиболее важных особенностей миграции в ряде стран происхождения и назначения мигрантов.

ОКСАНА АЛЬФРЕДОВНА ХАРАЕВА (oxa-na1@yandex.ru), МОСКОВСКИЙ ГОСУДАРСТВЕННЫЙ УНИВЕРСИТЕТ им. М.В. ЛОМОНОСОВА, РОССИЯ. 
Таким образом, четыре раздела книги охватывают широкий круг вопросов от анализа общих закономерностей развития постсоветской миграционной системы до тематических исследований особенностей миграции в ряде стран происхождения и назначения мигрантов. Первый раздел посвящен изучению общих тенденций развития миграционных процессов на постсоветском пространстве. Г. Йоффе описывает изменения в социально-экономическом положении бывших советских республик, последовавшие за распадом СССР, и выявляет основные факторы, определяющие направления межстрановой миграции на территории бывшего Советского Союза. Автор приходит к заключению, что в обозримом будущем, по всей вероятности, Россия останется главным центром притяжения мигрантов из бывших советских республик. Роль страны назначения мигрантов, хотя и в значительно меньшей степени, по мнению автора, будет выполнять также Белоруссия.

Подробный анализ тенденций и основных факторов постоянной миграции между постсоветскими странами представлен в следующей главе. Авторы М. Денисенко, Н. Мкртчян и О. Чудиновских рассматривают процесс трансформации миграционных связей государств, возникших на территории бывшего СССР, отмечая, что массовая миграция русскоязычного населения из стран Балтии, Закавказья и Центральной Азии в Россию, а также на Украину и в Белоруссию в 1990-х годах, носившая вынужденный характер, в дальнейшем сменилась заметно увеличившимися потоками коренных народов стран Центральной Азии в Россию и Казахстан. Результатом постсоветской миграции стало резкое возрастание доли титульных народов в составе населения многих государств, возникших на пространстве бывшего СССР. С другой стороны, новый характер миграционного взаимодействия между отдельными странами привел к появлению ранее не существовавших диаспор и развитию мигрантских сетей, особенно в больших городах.

Анализ потоков трудовой миграции в новых независимых государствах и их влияния на страны происхождения и назначения мигрантов продолжается в следующей главе. Среди факторов, определяющих масштаб и структуру трудовой миграции, авторы главы М. Денисенко и О. Чудиновских выделяют не только различия в экономических и демографических показателях стран региона, но также миграционную политику принимающих государств, отмечая, что на протяжении последних двадцати пяти лет можно было наблюдать примеры либерализации либо ужесточения миграционного законодательства, приводившие к сокращению или увеличению нелегальной миграции. Как показывает исследование, в целом трудовая миграция на постсоветском пространстве характеризуется сохраняющейся привлекательностью России как центра миграционной системы, преобладанием в составе трудовых мигрантов граждан стран Центральной Азии (главным образом, молодых мужчин без профессиональной подготовки), а также значительной долей мигрантов с неурегулированным статусом или работающих без разрешительных документов. Вместе с тем данные свидетельствуют, что постсоветское пространство больше не является замкнутой системой и все большее число мигрантов из стран, расположенных в европейской части бывшего СССР, ориентировано на трудоустройство в государствах ЕС.

Исследованию процессов эмиграции из стран СНГ посвящена последняя глава первого раздела. Автор, М. Денисенко, выделяет два периода в постсоветской истории эмиграции, которые характеризуются существенными различиями в масштабах, 
направлениях и каналах перемещений населения за пределы бывшего СССР. Первый период, начавшийся после распада Советского Союза и продолжавшийся до начала 2000-х годов, отличался высокими показателями эмиграции, выраженной этнической компонентой в составе миграционных потоков (в основном мигрировали немцы и евреи), а также отчетливым географическим фокусом: странами назначения для подавляющего числа мигрантов в эти годы были Израиль, Германия и США. Интенсивность миграционного оттока во втором периоде снизилась, при этом расширилась география стран назначения мигрантов. Одним из основных факторов сокращения оттока населения являлось исчерпание потенциала репатриации. В отличие от предшествующего десятилетия в 2000-е годы эмиграция была обусловлена, главным образом, экономическими мотивами. По оценкам автора, в постсоветский период за пределы границ бывшего СССР выехало на постоянное место жительства около 7400000 человек (99) ${ }^{1}$.

Во втором разделе представлен анализ тенденций миграции в отдельных странах бывшего СССР. Влияние эмиграции на численность и половозрастной состав населения Грузии обсуждается в исследовании, проведенном А. Сулаберидзе, И. Арчвадзе и В. Сулаберидзе. Особого внимания, по мнению авторов, заслуживают два вопроса. Первый - это трудовая миграция женщин, которая, с одной стороны, позволяет поддерживать уровень благосостояния семей, оставшихся в Грузии, и снимать напряжение на внутреннем рынке труда, с другой - оказывает негативное воздействие на демографическое развитие страны в долгосрочной перспективе. Второй - растущая склонность к миграции студентов, обусловленная высоким уровнем безработицы среди молодежи и низкой заработной платой и имеющая крайне отрицательные последствия для роста и развития интеллектуального потенциала государства. Следующая глава посвящена анализу краткосрочной и долгосрочной миграции населения Молдавии и ее влияния на социально-экономическое и демографическое развитие страны. Как отмечают авторы Т. Табак и О. Гагауз, массовая эмиграция стала главным фактором депопуляции, разрушения демографического потенциала и значительного ускорения процессов старения населения. Отличительной особенностью Молдавии является наличие выраженной двухвекторности миграционных потоков: один вектор направлен в сторону России, другой - в сторону стран Евросоюза, США и Канады. Данное обстоятельство в значительной степени влияет на внутреннюю и внешнюю политику государства, поскольку общество в Молдавии оказывается разделенным на два лагеря: сторонников укрепления социальноэкономических отношений с Россией и приверженцев расширения связей с ЕС. О. Малиновская далее характеризует основные этапы развития миграционных процессов на Украине. Автор подчеркивает растущее значение циркулярной миграции и расширение географии стран назначения мигрантов. В постсоветский период миграция сыграла важную роль социального амортизатора, позволившего снизить давление на рынок труда и улучшить благосостояние семей мигрантов, но в то же время для Украины это привело к потере части трудового и интеллектуального потенциала и усилению неблагоприятных тенденций демографического развития страны.

\footnotetext{
${ }^{1}$ При цитировании или отсылке к рецензируемой книге будет даваться только номер страницы. 
В следующих главах второго раздела рассматриваются вопросы трудоустройства и интеграции мигрантов в России как главной стране назначения на постсоветском пространстве. В. Мукомель анализирует условия вхождения и присутствия иностранных работников на российском рынке труда. Автор отмечает, что для всех контингентов мигрантов характерна нисходящая мобильность. Фактически, на рынке труда России не востребованы конкретные знания/навыки или уровень квалификации иностранных работников.

Е. Деминцева далее рассматривает пример формирования диаспоральной инфраструктуры в Москве мигрантами из Киргизии. Результаты глубинных интервью показывают, что киргизские мигранты активно используют собственные социальные сети и социальный капитал для создания агентств недвижимости, клиник и детских садов, услуги которых востребованы как среди их соотечественников, так и мигрантов из других стран. Появление таких институтов, по мнению автора, является реакцией на социальную изоляцию мигрантов в принимающем обществе. Большую роль в укреплении негативного отношения к миграции из стран Центральной Азии играют СМИ, которые формируют отрицательный образ мигрантов.

Е. Чернина предлагает вниманию читателей анализ трудовой миграции в Россию из Таджикистана. Автор рассматривает вопросы влияния на принятие решения о миграции характеристик потенциального мигранта. Результаты анализа свидетельствуют, что типичным таджикским мигрантом в начале 2010-х годов являлся мужчина 30 лет, член большого сельского домохозяйства (сын главы семьи, но уже имеющий свою семью). Решение о миграции выглядит как неосуществимое для наименее квалифицированных мигрантов и как непривлекательное для самых квалифицированных. Похожая ситуация наблюдается при оценке влияния уровня благосостояния домохозяйств: самые бедные домохозяйства наименее склоны к участию в миграции вследствие бюджетных ограничений, как и самые богатые, для которых существуют лучшие возможности жизни на родине.

В третьем разделе обсуждаются вопросы миграции в страны традиционного проживания выходцев из бывшего Советского Союза. Две первые главы посвящены мигрантам из бывшего СССР в Федеративной Республике Германии, которая приняла наибольшее число выбывших в страны дальнего зарубежья. Ф. Гетче, Дж. Эберле и Г. Брюкнер (F. Göttsche, J. Eberle, G. Brückner) анализируют территориальное распределение мигрантов из бывших советских республик в Германии, их социальнодемографические характеристики, присутствие на рынке труда и приходят к выводу, что они достаточно хорошо интегрированы по сравнению с другими мигрантами. Вместе с тем выходцы из бывшего СССР редко достигают высоких профессиональных позиций, несмотря на относительно высокий уровень образования.

Дж. Панайотидис (J. Panagiotidis) рассматривает правовые основы и интеграционные режимы постсоветской миграции в Германии, а также отдельные аспекты нынешнего положения иммигрантов из бывших союзных республик в немецком обществе, такие как использование языка и идентичность, стереотипы восприятия и предубеждение по 
отношению к постсоветским переселенцам, их политические установки и транснациональные практики.

Проблемы оттока из России в США представителей интеллектуальной элиты анализируются в главе, написанной А. Коробковым. Автор рассматривает масштаб, структурные характеристики и перспективы сотрудничества российской академической диаспоры с РФ и делает вывод, что Россия оказалась неспособна эффективно использовать потенциал своей интеллектуальной диаспоры. При этом нынешняя ситуация характеризуется дальнейшим обострением тех тенденций российской политической, социально-экономической и академической жизни, которые в значительной степени определили утечку умов. При отсутствии серьезного улучшения в этих областях и изменения тона российских отношений с Западом, по мнению автора, не приходится ожидать крупномасштабной возвратной миграции российских ученых или значительной активизации их сотрудничества с Россией.

Анализу еврейской эмиграции посвящена глава М. Тольца. Масштабы миграции в Израиль с 1989 г., по оценкам автора, составили около 1,1 млн человек (326). В работе показана решающая роль выталкивающих факторов в миграционном движении из стран бывшего Советского Союза, а также говорится о том, что социально-экономические проблемы в бывших советских республиках по-прежнему подталкивают евреев и их родственников к отъезду в довольно значительных масштабах. Так, по последним данным эмиграция из России в Израиль достигла 10500 человек (340), т. е. вернулась к уровню 1994 г., по оценкам автора.

Автор следующей главы Т. Еременко исследует особенности постсоветской волны эмиграции во Францию. Хотя численность переселенцев из бывшего СССР здесь меньше, чем в Израиле, Германии и США, наблюдается определенная селективность характеристик прибывших. Франция стала важным пунктом назначения для таких групп мигрантов, как студенты и лица, ищущие убежища. Отмечая значительную гетерогенность миграционных потоков из 12 стран СНГ, автор выделяет в их составе две группы: во-первых, это лица, прибывающие по линии воссоединения семей, с целью учебы или трудоустройства, вовторых, - вынужденные мигранты, спасающиеся от насилия и нестабильности в странах своего происхождения. Если первые имеют стабильный правовой статус, в большинстве своем владеют французским языком, имеют более высокую квалификацию и социальные связи в стране назначения, то вторые зачастую языка не знают, имеют более низкий уровень образования и в течение длительного периода находятся в стране с неурегулированным правовым статусом. Таким образом, ресурсы, которыми располагают мигранты, и условия приема сказываются на перспективах их интеграции.

Социально-экономические характеристики иммигрантов из бывшего СССР в Канаде и показатели их интеграции анализируют Ф. Ху и С. Ян (F. Hou, X. Yan). Авторы указывают на то, что большинство переселенцев из бывших советских республик прибыли в Канаду по каналам экономической иммиграции, т. е. были отобраны по критериям их соответствия характеристикам человеческого капитала и адаптивности. Данное обстоятельство объясняет более высокий уровень образования у постсоветских иммигрантов по сравнению с уроженцами Канады и другими группами иммигрантов. Выходцы из бывших советских 
республик лучше используют полученное образование, чем другие иммигранты. Их уровень занятости в среднем такой же, как у родившихся в Канаде. Вместе с тем постсоветские иммигранты отстают от канадских уроженцев по уровню заработной платы.

Четвертый раздел посвящен анализу новых маршрутов эмиграции. А. Буономо, Г. Габриелли и С. Строцца (А. Buonomo, G. Gabrielli, S. Strozza) рассматривают условия присутствия женщин из стран бывшего СССР на итальянском рынке труда. Женщины преобладают в составе постсоветских мигрантов в Италии. Высокий уровень образования позволяет им быстро найти работу. Женщины из новых независимых государств очень конкурентоспособны, уровень безработицы этой категории мигрантов ниже среднего значения для всего иностранного населения. Большинство женщин заняты в сфере предоставления услуг по уходу на дому и, таким образом, сталкиваются с проблемой недоиспользования своего образования и профессиональных навыков. Ф. Бенасси, O. Казакия и С. Строцца (F. Benassi, O. Casacchia, S. Strozza) исследуют демографические характеристики мигрантов из стран бывшего СССР и модели их расселения в Италии. Согласно результатам анализа расселение выходцев из стран бывшего СССР носит дисперсный характер. Ситуация может зависеть от особенностей миграционного профиля группы. При гендерном дисбалансе в пользу женщин группа в значительной степени ориентирована на удовлетворение спроса на услуги по уходу со стороны итальянских домохозяйств, следовательно, ее модель расселения близка к итальянской.

В следующей главе представлены результаты исследования, посвященного анализу опыта миграции молдаван в Испанию, также ставшую одним из центров притяжения мигрантов из новых независимых государств. С. Марку (S. Marcu) отмечает, что решение о миграции в Испанию не рассматривается только как средство спасения от бедности, страха и безработицы на родине. Для молодых молдаван, как и для большинства молодых европейцев, отъезд из страны воспринимается как возможность приобретения гибкости, автономии и нового опыта.

В главе Т.А. Ренвик, И. Ясинской-Лахти и С. Варьонен (Т. A. Renvik, I. JasinskajaLahti, Si. Varjonen) рассматриваются вопросы интеграции русскоязычных иммигрантов в Финляндии. Авторы отмечают, что в целом русскоязычное население хорошо интегрировано в финское общество. Однако, как показывают исследования, его представители достаточно часто сталкиваются с недоверием и дискриминацией на рынке труда, при поиске жилья и в других сферах жизни. Анализ показал важность формирования условий, при которых иммигранты смогут обрести чувство принадлежности к большому обществу.

И. Гёдри и 3. Чаньи (I. Gödri, Z. Csányi) представляют обзор тенденций миграции из стран бывшего СССР в Венгрию. Авторы анализируют социально-демографические характеристики и положение на рынке труда постсоветских иммигрантов, в большинстве своем - выходцев из Украины венгерского происхождения, а также России. Обе группы переселенцев характеризуются более высоким уровнем образования по сравнению с уроженцами Венгрии. Однако шансы мигрантов на трудоустройство ниже, чем у коренного населения. Высокая доля лиц с высшим образованием, занятых на позициях, не требующих 
такого уровня профессиональной подготовки, также свидетельствует о сложностях процесса интеграции мигрантов.

Следующая глава знакомит с исследованием постсоветской миграции в Польшу. 3. Брунарска говорит о значительной неоднородности состава мигрантов из бывшего СССР. Анализируя три наиболее многочисленные группы, автор отмечает, что миграция украинцев в Польшу носит, главным образом, временный характер, а структура потоков характеризуется высокой долей работников, занятых низкоквалифицированным трудом. Белорусы в большей степени ориентированы на переезд в Польшу на постоянное жительство. Выходцы из России часто демонстрируют такие же установки, но многие стремится к этому путем получения статуса беженца. В отличие от большинства мигрантов из других стран бывшего СССР среди лиц, прибывших из Белоруссии и России, выше удельный вес квалифицированных работников.

Завершается книга главой Д. Милютиной, представляющей анализ британской научной литературы по вопросам миграции из бывшего СССР, ее ключевых тем, а также проблем, присущих этому дискурсу. В частности, исследователи «постсоветских» мигрантов нередко демонстрируют упрощенный подход к определению групповых границ. Автор предлагает отойти от использования зонтичных терминов «русскоязычные» и/или «постсоветские», указывающих на недостаток внимания к культурным и политически значимым различиям внутри и между группами этого населения. Это имеет значение для формирования более объективного понимания миграционных процессов.

В заключение следует отметить, что рецензируемая книга является серьёзным вкладом в изучение постсоветской миграции. Она представляет комплексный анализ миграционных процессов почти за три последних десятилетия, ставших временем радикальной трансформации миграционной системы в результате распада СССР, в свою очередь определившей ряд политических, социально-экономических и демографических изменений в новых независимых государствах.

Вопросы, затронутые в исследовании, заслуживают дальнейшего изучения, вероятными направлениями которого могут стать исследования миграционного обмена государств СНГ с другими странами (Чехией, Австрией), анализ последствий миграции для стран оттока и стран приема мигрантов. Переписи населения раунда 2020-2021 гг. открывают перед исследователями дополнительные возможности для оценки миграции, изучения характеристик мигрантов, их места в жизни принимающего общества.

Книга, несомненно, вызовет интерес не только научного сообщества, но и читателей, пытающихся осмыслить значение миграции в развитии стран региона, их взаимоотношении друг с другом и остальным миром. 


\section{ЛИТЕРАТУРА}

Танги А. (2010). Размышление о миграции в постсоветских государствах. Антропологический форум, 13, 323-344. URL: http://anthropologie.kunstkamera.ru/files/pdf/013/13_tinguy.pdf

Денисенко М., Чудиновских О. (2012). Миграции между странами СНГ. Демоскоn Weekly, 533-534. URL: http://www.demoscope.ru/weekly/2012/0533/analit04.php

Denisenko M., Light M., Strozza S. (Eds.) (2020). Migration from the Newly Independent States: 25 Years After the Collapse of the USSR. Societies and Political Orders in Transition. Springer Nature Switzerland AG 2020. 


\title{
MIGRATION IN THE POST-SOVIET SPASE
}

\section{Review of the book «Migration from the Newly Independent \\ States: 25 years after the collapse of the USSR» \\ OXANA KHARAEVA}

\begin{abstract}
The monograph by a large group of authors from different countries, edited by M. Denisenko, M. Light and S. Strozza, contains a comprehensive analysis of the development of migration processes in the newly independent states that formed on the territory of the former USSR. Using a wide range of sources, it looks at the scale, trends and factors of migration, the socio-demographic characteristics of migrants and the situation of migrants in host countries. Much attention is paid to the research on the impact of migration on the countries of origin and destination of migrants.
\end{abstract}

Key words: migration, the newly independent states, diaspora, integration.

OXANA KHARAEva (oxa-na1@yandex.ru,), Lomonosov Moscow State University, Russia.

DATE RECEIVED: APRIL 2020.

\section{REFERENCES}

Tangi A. (2010). Razmyshleniye o migratsii v postsovetskikh gosudarstvakh [Thinking about migration in post-Soviet States]. Antropologicheskiy forum, 13, 323-344. (In Russ.). URL: http://anthropologie.kunstkamera.ru/files/pdf/013/13_tinguy.pdf

Denisenko M., Chudinovskikh O. (2012). Migratsii mezhdu stranami SNG [Migration between CIS countries]. Demoskop Weekly, 533-534. (In Russ.). URL: http://www.demoscope.ru/weekly/2012/0533/analit04.php

Denisenko M., Light M., Strozza S. (Eds.) (2020). Migration from the Newly Independent States: 25 Years After the Collapse of the USSR. Societies and Political Orders in Transition. Springer Nature Switzerland AG 2020. 